\title{
Effect of chronic nonmalignant pain on highway driving performance
}

\author{
D.S. Veldhuijzen ${ }^{\mathrm{a}, \mathrm{b}, *}$, A.J.M. van Wijck ${ }^{\mathrm{b}}$, F. Wille ${ }^{\mathrm{c}}$, J.C. Verster ${ }^{\mathrm{a}}$, J.L. Kenemans ${ }^{\mathrm{a}}$, \\ C.J. Kalkman ${ }^{\mathrm{b}}$, B. Olivier ${ }^{\mathrm{a}}$, E.R. Volkerts ${ }^{\mathrm{a}}$ \\ ${ }^{a}$ Utrecht Institute for Pharmaceutical Sciences, Rudolf Magnus Institute of Neuroscience, Department of Psychopharmacology, \\ University of Utrecht, P.O. Box 80082, 3508 TB, Utrecht, The Netherlands \\ ${ }^{\mathrm{b}}$ Pain Clinic, Department of Anesthesiology, University Medical Center Utrecht, P. O. Box 85500, 3508 GA, Utrecht, The Netherlands \\ ${ }^{\mathrm{c}}$ Pain Clinic, Department of Anesthesiology, Diakonessenhuis Utrecht, P.O. Box 80250, 3508 TG Utrecht, The Netherlands
}

Received 22 February 2005; received in revised form 28 November 2005; accepted 19 December 2005

\begin{abstract}
Most pain patients are treated in an outpatient setting and are engaged in daily activities including driving. Since several studies showed that cognitive functioning may be impaired in chronic nonmalignant pain, the question arises whether or not chronic nonmalignant pain affects driving performance. Therefore, the objective of the present study was to determine the effects of chronic nonmalignant pain on actual highway driving performance during normal traffic. Fourteen patients with chronic nonmalignant pain and 14 healthy controls, matched on age, educational level, and driving experience, participated in the study. Participants performed a standardized on-the-road driving test during normal traffic, on a primary highway. The primary parameter of the driving test is the Standard Deviation of Lateral Position (SDLP). In addition, driving-related skills (tracking, divided attention, and memory) were examined in the laboratory. Subjective assessments, such as pain intensity, and subjective driving quality, were rated on visual analogue scales. The results demonstrated that a subset of chronic nonmalignant pain patients had SDLPs that were higher than the matched healthy controls, indicating worse highway driving performance. Overall, there was a statistically significant difference in highway driving performance between the groups. Further, chronic nonmalignant pain patients rated their subjective driving quality to be normal, although their ratings were significantly lower than those of the healthy controls. No significant effects were found on the laboratory tests.

(C) 2005 International Association for the Study of Pain. Published by Elsevier B.V. All rights reserved.
\end{abstract}

Keywords: Pain; Driving ability; SDLP

\section{Introduction}

Most chronic nonmalignant pain patients engage in daily activities including driving. Driving a car is a complex task requiring mental alertness and a variety of cognitive functions such as perception, attention, learning, memory, and decision making (Walter et al., 2001). Several studies have demonstrated cognitive impairments on laboratory tasks in patients with chronic nonmalig-

\footnotetext{
${ }^{*}$ Corresponding author. Tel.: +31 30253 7764; fax: +3130253 7387.

E-mail address: D.S.Veldhuijzen@pharm.uu.nl (D.S. Veldhuijzen).
}

nant pain, particularly on measures assessing attentional capacity, processing speed, and psychomotor speed (e.g., Grisart and Plaghki, 1999; Hart et al., 2000; Sjögren et al., 2005). These findings suggest that car driving performance may be impaired in chronic nonmalignant pain patients, although it should be noted that some studies only reported specific cognitive deficits (e.g., Apkarian et al., 2004) or even failed to find any effect of chronic pain on cognition (e.g., Brown et al., 2002).

A recent longitudinal epidemiological study suggested that either pain, pain medication or a combination of these was associated with traffic accident involvement in middle-aged (aged above 35 and below 65 years) 
drivers (Lagarde et al., 2005). Unfortunately, the effects of pain and pain medication could not be disentangled in this study. Further, epidemiological studies have indicated that other medical conditions, such as dementia, diabetes, cardiovascular disorders, strokes, and arthritis among females, may also increase the risk of being involved in motor vehicle collisions, particularly in older (aged 65 years and older) drivers (Kaszniak et al., 1991; Koepsell et al., 1994; McGwin et al., 2000).

Many pain patients use medicinal drugs on a regular basis to ameliorate their pain. Of specific concern are the drugs with central nervous system (CNS) side effects, so-called psychotropic drugs. The occurrence of CNS side effects, such as drowsiness, concentration problems, and slowness of responding, may be problematic in terms of traffic safety. Opioids are one of the most commonly used psychotropic drugs in the treatment of pain. Several studies demonstrated that chronic pain patients, while on opioid therapy, do not show impairment in driving simulator tests or on driving-related skills (e.g., Galski et al., 2000; Fishbain et al., 2003; Sabatowski et al., 2003; Menefee et al., 2004; Byas-Smith et al., 2005). Unfortunately, because of the complex interaction between effects of pain on the one hand and effects of drug treatment (clinical efficacy versus side effects) on the other hand, study outcomes are difficult to interpret. First, pain itself may impair driving performance. Second, side effects of psychotropic drugs may also impair driving ability. Third, these side effects may, however, diminish after repeated daily drug use (Dellemijn et al., 1998). Finally, if pain itself impairs driving, efficient pain relief may even improve driving performance. Hence, understanding the effects of pain itself on driving performance is necessary to enable unraveling the effects of pain medication on driving performance.

In this context, the present study was designed to investigate the effects of chronic nonmalignant pain on actual driving performance during normal traffic, on a primary highway. In addition to the on-the-road driving test, psychomotor, attention, and memory tests measuring driving-related skills were conducted in the laboratory.

\section{Methods}

\subsection{Participants}

Participants were 14 patients with chronic nonmalignant pain (4 females and 10 males, mean age $46.9(\mathrm{SD}=8.5)$ years, age ranged between 31 and 58 years) and 14 healthy controls (seven females and seven males, mean age $50(\mathrm{SD}=7.5)$ years, age ranged between 34 and 58 years). Demographic variables of participants are depicted in Table 1. Patients were recruited from April to December 2004 by two pain clinics in Utrecht, the Netherlands: the University Medical Center, and the general hospital Diakonessenhuis. Patients were included if they had nonmalignant pain of at least moderate intensity (at least 4 on a $10 \mathrm{~cm}$ scale) for at least three months, measured with a Visual Analogue Scale (VAS) by the pain physician. Table 2 displays pain descriptors for each patient separately. Note that although at inclusion pain patients had VAS pain intensity scores of at least $4 \mathrm{~cm}$, on the actual testday, VAS pain intensity scores were lower than $4 \mathrm{~cm}$ for several patients, which demonstrates that pain intensity scores may vary greatly from day to day.

Healthy controls were recruited by local newspaper advertisement. From a pool of 30 healthy controls, 14 participants were chosen, who matched with pain patients on age, driving experience (amount of kilometers driven the past year), and educational level. Educational level was scored according to the 5 categories described in the Wechsler Adult Intelligence Scale (WAIS; Wechsler, 2000).

All participants were right-handed and had normal or corrected to normal vision. They possessed a valid driver's license. Participants were included if they smoked less than 15 cigarettes a day. Three out of 14 chronic pain patients smoked (mean number of cigarettes a day for these three participants: $7.3, \mathrm{SD}=6.8$ ) and 2 out of 14 healthy controls smoked, although rarely (mean number of cigarettes a day for these 2 participants: $0.8, \mathrm{SD}=0.4$ ). From midnight prior to participation, the use of caffeine, nicotine, and alcohol was prohibited. None of the participants used psychotropic medication. The use of paracetamol and/or nonsteroidal anti-inflammatory drugs (NSAIDs) was discouraged but allowed. Participants were excluded from the study if they were not able to abstain from psychotropic medication, suffered from alcohol or drug dependence, psychological or psychiatric disorders or severe physical disorders. The use of drugs of abuse (amphetamines, barbiturates, benzodiazepines, cocaine, morphine, and THC) was tested using a urine drug detection device. The use of

Table 1

Demographics of participants

\begin{tabular}{lccc}
\hline & Pain patients Mean $( \pm$ SD) & Healthy controls Mean $( \pm$ SD) & $P$ value \\
\hline Age (years) & $46.9(8.5)$ & $50.0(7.5)$ & n.s. \\
NLV IQ & $94.5(9.6)$ & $105.6(7.1)$ & .002 \\
Years of education & $12.8(3.4)$ & $14.1(4.0)$ & n.s. \\
Educational level & $3.0(1.2)$ & $3.6(1.0)$ & n.s. \\
Driving experience $(\mathrm{km} /$ year) & $21,714.3(14,938.0)$ & $18,250.0(12,653.3)$ & n.s. \\
\hline
\end{tabular}

Abbreviations: n.s., not significant; SD, standard deviation. Educational level was scored according to the 5 categories described in the Wechsler Adult Intelligence Scale; 1, primary education; 2, secondary education; 3, extended secondary education; 4, higher nonacademic education; 5, academic education. 
Table 2

Pain-related demographic information displayed for each patient separately

\begin{tabular}{|c|c|c|c|c|}
\hline Patient No./Sex/Age (years) & Diagnosis & $\begin{array}{l}\text { Duration of pain } \\
\text { complaints (months) }^{\mathrm{a}}\end{array}$ & $\begin{array}{l}\text { VAS pain } \\
\text { intensity }(\mathrm{cm})^{\mathrm{a}}\end{array}$ & Analgesic medication \\
\hline $1 / \mathrm{F} / 31$ & Low back pain & 48 & 2.7 & Paracetamol, nabumeton \\
\hline 2/M/49 & Failed back surgery syndrome & 48 & 1.2 & Paracetamol \\
\hline $3 / \mathrm{M} / 51$ & Radiculopathy L5 & 12 & 5.0 & None \\
\hline $4 / \mathrm{M} / 56$ & Low back pain & 84 & 3.4 & None \\
\hline $5 / \mathrm{M} / 57$ & Pain in lower limbs & 36 & 3.1 & None \\
\hline $6 / \mathrm{M} / 58$ & Low back pain & 240 & 3.7 & None \\
\hline $7 / \mathrm{M} / 44$ & $\begin{array}{l}\text { Low back pain combined with } \\
\text { radiculopathy L5 }\end{array}$ & 60 & 5.4 & None \\
\hline $8 / \mathrm{M} / 40$ & Low back pain with neuropathy & 144 & 5.6 & None \\
\hline $9 / \mathrm{F} / 40$ & Low back pain & 240 & 4.3 & None \\
\hline $10 / \mathrm{F} / 50$ & Low back pain & 132 & 9.9 & $\begin{array}{l}\text { Celecoxib }^{b} \text {, paracetamol, } \\
\text { ibuprofen }\end{array}$ \\
\hline $11 / \mathrm{F} / 49$ & Painful scar in ankle & 120 & 6.8 & Paracetamol \\
\hline $12 / \mathrm{M} / 39$ & Low back pain & 84 & 7.3 & Rofecoxib, paracetamol \\
\hline $13 / \mathrm{M} / 56$ & Radiculopathy S1 right & 48 & 6.6 & Valdecoxib $^{\mathrm{b}}$ \\
\hline $14 / \mathrm{M} / 37$ & Painful scar in knee & 24 & 2.8 & Etoricox \\
\hline
\end{tabular}

Abbreviations: F, female; M, male; SI, sacroiliac; S, sacral; L, lumbar.

${ }^{\text {a }}$ Mean VAS score was $4.8 \mathrm{~cm}(\mathrm{SD}=2.3$, range $1.2-9.9 \mathrm{~cm})$ and mean duration of pain complaints was $94.3 \mathrm{months}(\mathrm{SD}=73.4$, range $12-240$ months).

b Medication used on testday.

alcohol was tested with a breath alcohol analyzer. The Medical Ethics Committee approved the study protocol and written informed consent was obtained from all participants. Procedures were in compliance with the Declaration of Helsinki and its latest amendments.

\subsection{Procedure}

A training session was held approximately two weeks before the actual test session to familiarize participants with the test procedures. On arrival at the Institute, inclusion and exclusion criteria were verified. On the day of testing, participants completed various questionnaires and were then transported to the highway, where they performed the driving test. Back at the Institute, after a standardized meal, the laboratory tests were performed.

\subsection{Driving test}

The on-the-road driving test is a standardized test, which has been applied in over 50 studies in recent years to examine the effects of psychotropic drugs on actual driving performance, including alcohol, hypnotics, antihistamines, and tricyclic antidepressants (e.g., Ramaekers, 2003; Verster and Volkerts, 2004; Verster et al., 2004).

The driving test was performed during normal traffic over a $100-\mathrm{km}$ track on a primary highway running between two cities (Utrecht and Arnhem). The highway consisted of two traffic lanes in both directions. Participants were instructed to drive with a steady lateral position, i.e., they were allowed to choose their own lateral position on the road, however, they were then requested to maintain this position as well as they could, within the right traffic lane while maintaining a constant speed of $95 \mathrm{~km} / \mathrm{h}$. Participants were allowed to overtake slower moving vehicles. A licensed driving instructor had access to a brake and clutch system and accompanied the participant, guarding safety during the test. A camera mounted on the roof of the car continuously recorded the position of the car within the traffic lane, by tracking the relative distance of the car from the delineated stripe in the middle of the road. The vehicle's speed and lateral position were continuously recorded, digitally sampled at $2 \mathrm{~Hz}$, and edited off-line to remove data that were disturbed by extraneous events (e.g., overtaking maneuvers, traffic jam). The primary outcome parameter is the standard deviation of lateral position (SDLP, in $\mathrm{cm}$ ), measuring the amount of weaving of the car within the right traffic lane. Further, the standard deviation of speed (SDS, km/h), mean speed $(\mathrm{MS}, \mathrm{km} / \mathrm{h})$, and mean lateral position (MLP, $\mathrm{cm}$ ) were recorded. Duration of the driving task was approximately $75 \mathrm{~min}$.

It is reasonable to assume that SDLP represents overall highway driving ability since it encompasses several levels of information processing which are combined to an integrated driving model (Ranney, 1994; Verster, 2002). For example, basic vehicle control, such as road tracking, is required involving automatic or effortless performances. Further, negotiation of common driving situations, such as curves, intersections, and gap acceptance, requires controlled processing, which is more effortful. Also, subjects are required to determine motivational aspects (i.e., to select the amount of risk they are willing to take) and risk evaluation. Since SDLP increment ultimately results in lane crossing into the adjacent traffic lane, SDLP can be regarded as an index of driving safety. Furthermore, this test is performed during normal traffic; hence, the onthe-road driving test is a close representation of normal driving.

\subsection{Laboratory tests}

Laboratory tests were performed in a dimly illuminated soundproof test room. 


\subsubsection{The tracking test}

Participants were instructed to keep an unstable moving bar in the middle of a horizontal plane (Jex et al., 1966). They could counteract or reverse the movements of the unstable bar with the aid of a computer mouse. The root mean square of the tracking error (RMS) is the outcome of this test. Total time on task was approximately $4 \mathrm{~min}$.

\subsubsection{Sternberg memory scanning test (Fixed version)}

After learning a fixed memory set of four digits, single digits were subsequently presented on the computer screen (Sternberg, 1966). By button-press, participants had to indicate whether a digit was shown beforehand or not. The mean reaction time $(\mathrm{RT}, \mathrm{ms})$ and percentage of errors are the parameters of interest. Total time on task was approximately $4 \mathrm{~min}$.

\subsubsection{Divided attention test}

In the divided attention test, the Sternberg memory scanning test and the tracking test were performed simultaneously. Parameters of the divided attention test are the RMS, RT (ms), and percentage of errors. Total time on task was approximately $8 \mathrm{~min}$.

\subsection{Subjective assessments}

\subsubsection{General functioning}

The following scales were administered to assess depression, anxiety, and quality of life: Beck Depression Inventory (BDI; Beck et al., 1961), Spielberger State-Trait Anxiety scales (STAI; Spielberger, 1983), and Short Form 36 Health Survey (SF-36; Ware et al., 1993). A global measure of intelligence (IQ) was obtained using the Dutch reading test for adults (NLV; Schmand et al., 1992), adapted from the National Adult Reading Test. Participants read out loud 50 words. Total correctly pronounced words were converted to an estimate of IQ.

\subsubsection{Pain}

Pain intensity was assessed with a Visual Analogue Scale (VAS) using the McGill Pain Questionnaire (MPQ; Melzack, 1975). Coping strategies were assessed with the Coping with Pain Questionnaire (CPQ), adapted from the Coping Strategy Questionnaire (CSQ; Rosenstiel and Keefe, 1983).

\subsubsection{Driving}

Before and after the driving test the participants indicated their alertness on a 21-point scale. Further, participants indicated the perceived quality of their driving performance using a $20 \mathrm{~cm}$ scale that varied from 'I drove exceptionally poor' to 'I drove exceptionally well' around a midpoint of 'I drove normally'. Also, they indicated the level of effort they had to invest during driving on a $15 \mathrm{~cm}$ scale.

\subsection{Statistical analysis and power estimates}

A priori sample size estimation of 28 participants was based upon the primary outcome measure, SDLP. Based upon results from previous studies, this study was designed to detect a SDLP difference of $2.4 \mathrm{~cm}$, with a standard deviation of
$3.0 \mathrm{~cm}$ and with at least $90 \%$ power using a one-sided test at the .05 significance level. Because patient recruitment was slower than expected, an interim analysis of the results of the study was conducted after enrollment of half of the patients to enable the study to be stopped early if a clear result emerged.

Statistical analysis was performed by univariate analysis of variance (ANOVA) with Group as between-subjects factor. IQ and Gender were included as covariates in the analyses, as groups differed on these variables. Time-on-task effects for SDLP scores were tested in a repeated-measures ANOVA with between-subjects factor Group and with two within-subjects factors: Direction (2 levels: first versus latter part of the test) and Road Segment (5 levels: for each $10 \mathrm{~km}$ segment per direction; the 5 segments within each half of the trip were included into the model mirrorwise (1st versus 10th, 2nd versus 9th, etc.)). Visual analogue scales assessing alertness were analyzed by ANOVA for repeated measures with Group and Time (before versus after the driving test) as between-subjects factors. Statistical analyses of data that were not normally distributed were performed using the Wilcoxon nonparametric test for two related samples. For all tests a critical $\alpha$-level of .05 was used. Statistical analyses were performed with SPSS 11.0.1 for Windows.

\section{Results}

\subsection{Subject demographics}

Table 1 shows baseline characteristics of both groups. Patients and controls were of similar age, did not differ in the amount of kilometers driven in the last year, or in educational level. However, a significant difference was found for the IQ scores measured with the NLV $(P=.002)$, indicating that pain patients had lower IQ scores in comparison to healthy controls.

\subsection{Driving test}

Mean and individual SDLP values for pain patients and healthy controls are depicted in Fig. 1. Statistical analysis revealed a significant group effect $(P=.007)$ for SDLP scores. Mean SDLP was higher, indicating worse highway driving performance, in pain patients compared to healthy controls: $25.2 \mathrm{~cm} \quad(\mathrm{SD}=4.6$, range $=18.3-34.1 \mathrm{~cm}) \quad$ versus $\quad 20.7 \mathrm{~cm} \quad(\mathrm{SD}=3.4$, range $=13.2-25.8 \mathrm{~cm}$ ), respectively. The difference in SDLP scores between groups was $4.5 \mathrm{~cm}$. The individual SDLP values depicted in Fig. 1 show that a subset of chronic nonmalignant pain patients had SDLP scores that were higher than those of the matched healthy controls, while SDLP values of the rest of the chronic pain patients appear to fall within the range of the healthy controls. No outliers were found in either group.

Mean SDLP over distance traveled is depicted in Fig. 2. It is evident from Fig. 2 that over the entire course of the driving test, pain patients had higher mean SDLP values than healthy controls. This group 


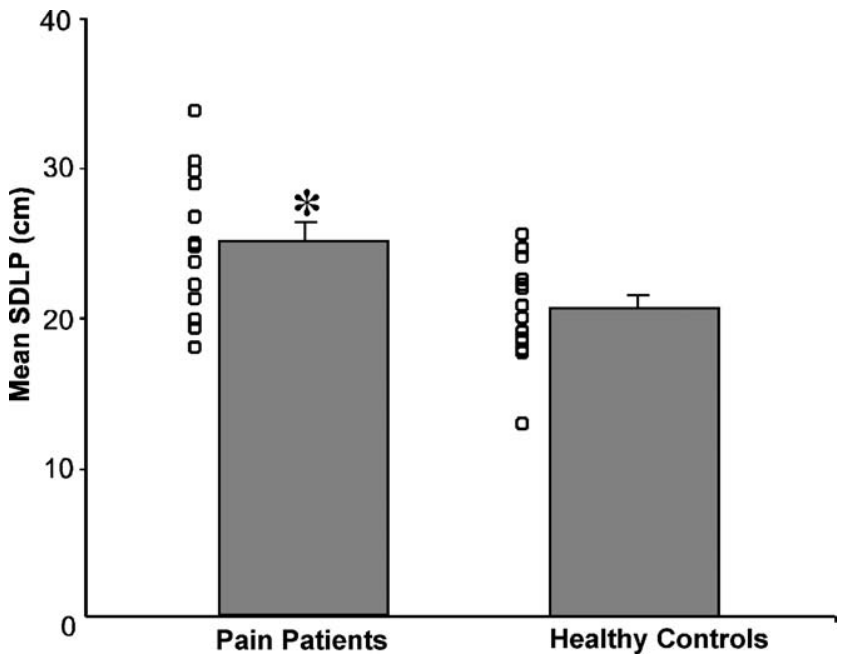

Fig. 1. Mean standard deviation of lateral position (SDLP) in centimeters $(\mathrm{cm}) \pm$ standard error. ${ }^{*} P<.007$ pain patients compared to healthy controls. The open squares plotted to the left of the bars represent the individual scores per group.

difference appears from the very beginning and is quite constant throughout the driving task.

Since pain patients and healthy controls differed significantly in IQ scores, correlations between IQ and SDLP were calculated. Statistical analysis did not reveal significant correlations between these variables in both groups. An additional analysis was performed to confirm these findings in which IQ was taken into account as a covariate in the analysis of SDLP differences. SDLP differences however remained significant $(P=.030)$. Even when the factor Gender was taken into account as a covariate besides IQ, SDLP group differences remained significant $(P=.038)$.

No significant correlations were found between SDLP and VAS pain intensity scores in the pain patients group, neither when the group was analyzed as a whole, nor when the group was separated in a low and a high pain group according to the median VAS score (which was $5.0 \mathrm{~cm}$ ).

Furthermore, no significant differences between groups were found on mean speed, SD of speed, and mean lateral position (measuring the position of the car on the road). No excursions out of lane were observed in the adjacent lane in either group. Excursions out of lane into the road shoulder were more commonly observed in both groups, however, no significant differences were found between groups.

In addition, differences between groups in time-ontask effects for SDLP scores were analyzed. A significant main effect of group was found $(P=.031)$, indicating that pain patients had higher SDLP scores than those of the healthy controls. However, group differences were not found for any variable. A significant main effect of road segment was found $(P=.0001)$. SDLP values in segments 4 (first part of the trip: $30-40 \mathrm{~km}$ ) and 7 (second part of the trip: $60-70 \mathrm{~km}$ ) were significantly higher than the other segments. This finding might be explained by specific road parameters such as, for example, curvature of the road. However, of importance, pain patients and healthy controls did not differ in this respect since no significant interaction with group was found.

\subsection{Subjective assessments}

Overall, participants scored within the normal range on the BDI depression scale and on the STAI anxiety scale. No significant differences were found between pain patients and healthy controls on the coping with pain questionnaire. Pain patients scored significantly lower on most scales of the quality of life SF-36 survey in comparison to healthy controls: general health $(P=.003)$, mental health $(P=.019)$, physical functioning $(P=.001)$, role functioning-physical $(P=.003)$, social functioning $(P=.001)$, bodily pain $(P=.001)$, and vitality $(P=.002)$. No differences between groups

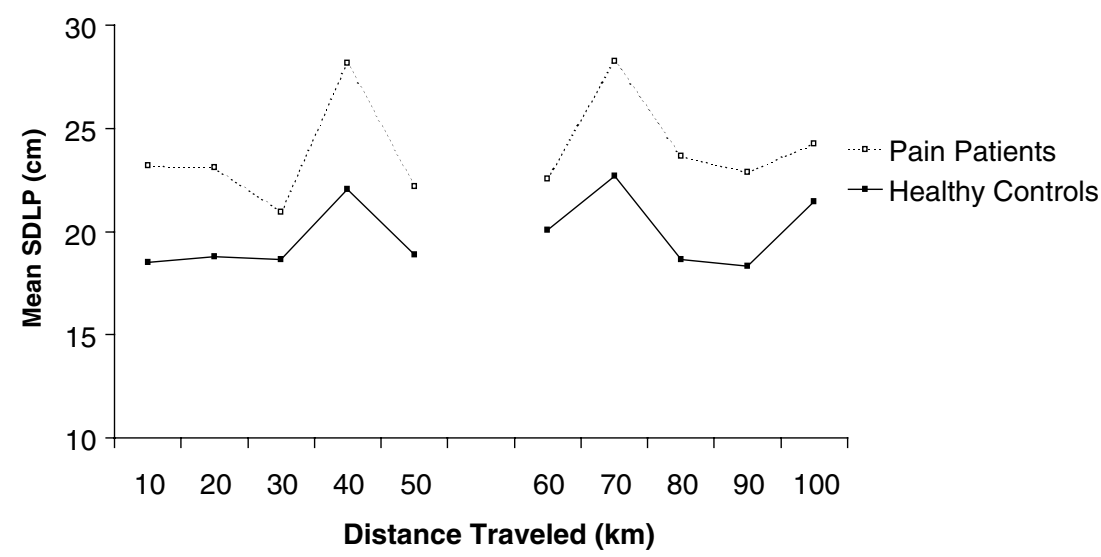

Fig. 2. Mean SDLP over distance traveled, separately for both groups. The break in the graph represents the turning point; the first part of the graph shows the $50-\mathrm{km}$ track to the turning point, the second part of the graph shows the return trip. 
were found on scales measuring interference of emotional problems with work or daily activities and health changes during the past week.

Ratings of subjective driving quality of both groups were around the point of $10 \mathrm{~cm}$ at a $20 \mathrm{~cm}$ scale, indicating "I drove normally". Pain patients scored a mean of $10.7(\mathrm{SD}=2.1)$ and healthy controls a mean of 13.5 $(\mathrm{SD}=2.1)$. However, ratings of subjective driving quality were significantly lower in the chronic nonmalignant pain patient group than in the healthy control group $(P=.009)$. No statistically significant difference between groups was found concerning mental effort during driving. Mean mental effort score of pain patients was 5.7 $(\mathrm{SD}=1.8)$ and that of healthy controls $4.6(\mathrm{SD}=1.9)$. Pain patients reported to be significantly less alert $(P=.019)$, both before and after the driving test, compared to the healthy controls. Mean alertness scores of pain patients was $8.5(\mathrm{SD}=4.4)$ and for healthy controls 5.0 $(\mathrm{SD}=2.9)$. Further, a significant effect of time was found $(P=.0001)$, indicating that participants were significantly less alert after the driving test than before the driving test. No significant interaction between group and time was found, indicating that the decrement in alertness over time was the same in both groups. None of the subjective assessments related to driving correlated significantly with SDLP.

\subsection{Laboratory test performance}

Laboratory test results are summarized in Table 3. Performance on laboratory tests did not result in significant differences between groups, indicating that performance of pain patients was comparable to that of healthy controls. None of the laboratory test parameters correlated significantly with SDLP.

\section{Discussion}

Findings of the present study demonstrate that a subset of chronic nonmalignant pain patients showed SDLPs that were higher than those of matched healthy

Table 3

Means $( \pm \mathrm{SD})$ are presented for the laboratory test results

\begin{tabular}{lccc}
\hline & Pain patients & Healthy controls & $P$ value \\
\hline Tracking test (RMS) & $16.3(8.9)$ & $12.8(5.8)$ & .222 \\
Sternberg memory scanning test & & \\
$\quad$ Reaction time (ms) & $773.3(302.2)$ & $713.3(119.7)$ & .496 \\
$\quad$ Errors (\%) & $1.5(1.9)$ & $1.1(1.0)$ & .593 \\
$\begin{array}{l}\text { Divided attention test } \\
\quad \text { Tracking (RMS) }\end{array}$ & $22.0(8.6)$ & $20.7(8.6)$ & .677 \\
Sternberg memory scanning & & \\
$\quad$ Reaction time (ms) & $835.4(326.9)$ & $778.0(149.7)$ & .596 \\
$\quad$ Errors (\%) & $4.4(4.3)$ & $2.3(1.2)$ & .272 \\
\hline
\end{tabular}

Abbreviations: SD, standard deviation; RMS, root mean square; ms, milliseconds. controls. Overall, there was a statistically significant difference in SDLPs between the groups. This difference in SDLP between groups of $4.5 \mathrm{~cm}$ corresponds to that observed in healthy volunteers after consuming alcohol up to a blood alcohol concentration of $0.08 \%$ (Louwerens et al., 1987), which is above the legal limit for driving a car in many countries. It has been established that with an alcohol level of $0.08 \%$, the estimated probability of causing an accident is approximately three times higher than for sober drivers, and that this probability rises exponentially with higher alcohol levels (Borkenstein et al., 1964; Hingson and Winter, 2003). Thus, the clinical relevance of the observed worse highway driving performance in the subset of chronic nonmalignant pain patients, as presented in Fig. 1, is evident.

Further, chronic nonmalignant pain patients rated their subjective driving quality significantly lower than healthy controls, however, scores were still in the range of normal driving.

In contrast to the on-the-road driving test, laboratory tests are intended to measure specific skills and abilities that are involved in driving under controlled circumstances. These laboratory tests obviously do not cover driving ability as a whole. In the laboratory, no significant differences between groups were found on tracking, divided attention, and memory tests. These tests included behavioral response areas that are representative of the demands of driving and are generally found to be the most sensitive to the effects of alcohol (Moskowitz and Fiorentine, 2000). The discrepancy of finding impaired on-the-road driving performance versus absence of significantly impaired laboratory test performance is in line with earlier findings that isolated driving-related skills and abilities tested in the laboratory do not predict actual driving performance as a whole (Verster, 2002). It remains to be determined which of the variety of skills that are related to driving ability is impaired in chronic nonmalignant pain patients. Possible candidates are vigilance (sustained attention) or attention capacity (the amount of which pain processing and high demanding task performance share limited attentional resources).

Future studies will need to examine a larger, more diverse sample of chronic pain patients in order to determine the generalizability of the present findings. In the present study, a selected subgroup of pain patients entering a specialized pain clinic was included. Mean age of the included patients was presumably lower than that of the average chronic pain patient visiting a pain clinic, and patients were only treated with NSAIDs and/or acetaminophen. Further, most patients included in this study suffered from low back pain. Hence, other pain conditions such as chronic headache, musculoskeletal pain, and neuropathies should be studied, and the influence of variables such as age and gender should be examined as well. The results are not generalizable 
to patients with acute pain or to pain complaints of short duration. Further, it is important to note that there are wide individual differences in reports of pain intensity. Some individuals with pain may therefore be more capable of driving than others. In this context, Sjögren et al. (2000) discussed the complicated factor that pain itself may have an arousal effect that may improve functioning, while pain on the other hand may also lessen the ability to concentrate.

The present results indicate that different levels of pain intensity (e.g., mild, moderate, and severe) do not impair highway driving in a dose-response fashion, as no significant correlation was found between SDLP and VAS pain intensity scores in the pain patient group. These results suggest that the simple fact of having pain may cause decrements in driving performance, not the severity of pain complaints. This finding is in line with results of Kuhajda et al. (2002) who suggested that pain may operate at a threshold level rather than on a doseresponse continuum. However, group sizes of the present study were too small to conclusively state this. Therefore, in future studies it would be interesting to address the question to what extent the degree of pain intensity is associated with poorer driving performance in a larger sample.

Patients were asked not to use analgesic medication during the investigation, since possible CNS side effects of medication or pain relief might affect driving ability. However, the use of paracetamol and/ or NSAIDs was not prohibited in this study to allow escape medication when needed and to avoid dropouts because of severe pain.

No effects have been observed of paracetamol on cognitive task performance (Bradley and Nicholson, 1987). Inconclusive results have been found regarding effects of NSAIDs on cognition. In general, CNS side effects occur infrequent, are mild of intensity, and are most often reported by elderly (Wysenbeek et al., 1988; Hanlon et al., 1997). Therefore, it is unlikely that the use of NSAIDs did influence the results of our study. Seven of 14 pain patients used paracetamol and/or NSAIDs during the study, but only two of them on the testday. Post hoc analysis showed that SDLP differences between groups remained significant when the two patients who used analgesics on the testday and their matched healthy controls were omitted from the analysis $(P=.046)$. Moreover, no significant differences were found between SDLP values for the seven patients who used analgesics and the seven patients who did not $(P=.40)$.

In summary, the results of the present study demonstrate that a subset of chronic nonmalignant pain patients showed SDLPs that were higher than those of matched healthy controls, which resulted in an overall statistically significant difference in SDLP between groups. Further studies should be conducted to specify which chronic nonmalignant pain patients are at risk for worsened driving performance. Further, the effects of chronic nonmalignant pain on driving performance should be established under more specific circumstances such as city driving. Furthermore, future research on driving ability in chronic nonmalignant pain patients should focus on disentangling the complex interaction between treatment efficacy (e.g., possible improvement in driving performance caused by pain reduction) and adverse drug effects (e.g., possible driving impairment caused by adverse drug effects), particularly for psychotropic medicinal drugs.

\section{Acknowledgments}

The authors thank Martine de Bruin, Charlene Matthews, and Marieke Siepert for assisting in subject recruitment and testing.

\section{References}

Apkarian AV, Sosa Y, Krauss BR, Thomas PS, Fredrickson BE, Levy $\mathrm{RE}$, et al. Chronic pain patients are impaired on an emotional decision-making task. Pain 2004;108:129-36.

Beck AT, Ward CH, Mendelson M, Mock JE, Erbaugh JK. An inventory for measuring depression. Arch Gen Psychiatry 1961;4:561-71.

Borkenstein RF, Crowther FR, Shumate RP, Ziel WB, Zylman R. The role of the drinking driver in traffic accidents. Indiana University: Department of Police Administration; 1964.

Bradley CM, Nicholson AN. Studies on performance with aspirin and paracetamol and with centrally acting analgesics meptazinol and pentazocine. Eur J Clin Pharmacol 1987;32:135-9.

Brown SC, Glass JM, Park DC. The relationship of pain and depression to cognitive function in rheumatoid arthritis patients. Pain 2002;96:279-84.

Byas-Smith MG, Chapman SL, Reed B, Cotsonis G. The effect of opioids on driving and psychomotor performance in patients with chronic pain. Clin J Pain 2005;21:345-52.

Dellemijn PL, van Duijn H, Vanneste JA. Prolonged treatment with transdermal fentanyl in neuropathic pain. J Pain Symptom Manage 1998;16:220-9.

Fishbain DA, Cutler RB, Rosomoff HL, Rosomoff RS. Are opioiddependent/tolerant patients impaired in driving-related skills? A structured evidence-based review. J Pain Symptom Manage 2003;25:559-77.

Galski T, Williams JB, Ehle HT. Effects of opioids on driving ability. J Pain Symptom Manage 2000;19:200-8.

Grisart JM, Plaghki LH. Impaired selective attention in chronic pain patients. Eur J Pain 1999;3:325-33.

Hanlon JT, Schmader KE, Landerman LR, et al. Relation of prescription nonsteriodal antiinflammatory drug use to cognitive function among community-dwelling elderly. Ann Epidemiol 1997;7:87-94.

Hart RP, Martelli MF, Zasler ND. Chronic pain and neuropsychological functioning. Neuropsychol Rev 2000;10:131-49.

Hingson R, Winter M. Epidemiology and consequences of drinking and driving. Alcohol Res Health 2003;27:63-78.

Jex HR, McDonell JD, Phatak AV. Critical tracking test for manual control research. IEEE Trans Hum Fac Electron 1966;7:138-45. 
Kaszniak AW, Keyl PM, Albert MS. Dementia and the older driver. Hum Factors 1991;33:527-37.

Koepsell TD, Wolf M, McCloskey L, Buchner DM, Louie D, Wagner EH. Medical conditions and motor vehicle collision injuries in older adults. J Am Geriatr Soc 1994;42:695-700.

Kuhajda MC, Thorn BE, Klinger MR, Rubin NJ. The effect of headache pain on attention (encoding) and memory (recognition). Pain 2002;97:213-21.

Lagarde E, Chastang JF, Lafont S, Coeuret-Pellicer M, Chiron M. Pain and pain treatment were associated with traffic accident involvement in a cohort of middle-aged workers. J Clin Epidemiol 2005;58:524-31.

Louwerens JW, Gloerich ABM, De Vries G. The relationship between drivers' blood alcohol concentration (BAC) and actual driving performance during high speed travel. In: Noordzij PC, Roszbach R, editors. Alcohol, drugs and traffic safety. Proceedings of the 10th international conference on alcohol, drugs and traffic safety. Amsterdam: Excerpta Medica; 1987. p. $183-92$.

McGwin G, Sims RV, Pulley L, Roseman JM. Relations among chronic medical conditions, medications, and automobile crashes in the elderly: a population-based case-control study. Am J Epidemiol 2000;152:424-31.

Melzack R. The McGill pain questionnaire: Major properties and scoring methods. Pain 1975;1:277-99.

Menefee LA, Frank ED, Crerand C, Jalali S, Park J, Sanschagrin K, Besser M. The effects of transdermal fentanyl on driving, cognitive performance, and balance in patients with chronic nonmalignant pain conditions. Pain Med 2004;5:42-9.

Moskowitz H, Fiorentine D. A review of the literature on the effects of low doses of alcohol on driving-related skills. Washington DC, USA: National Highway Traffic Safety Administration NHTSA, Report DOT HS-809-028, 2000.

Ramaekers JG. Antidepressants and driver impairment: empirical evidence from a standard on-the-road test. J Clin Psychiatry 2003;64:20-9.

Ranney TA. Models of driving behavior: a review of their evolution. Accid Anal Prev 1994;26:733-50.
Rosenstiel AK, Keefe FJ. The use of coping strategies in chronic low back pain patients: relationship to patient characteristics and current adjustment. Pain 1983;17:33-44.

Sabatowski R, Schwalen S, Rettig K, Herberg KW, Kasper SM, Radbruch L. Driving ability under long-term treatment with transdermal fentanyl. J Pain Symptom Manage 2003;25:38-47.

Schmand B, Lindeboom J, van Jarskamp F. Manual for the Dutch reading test for adults. Lisse, the Netherlands: Swets \& Zeitlinger B.V.; 1992.

Sjögren P, Christrup LL, Petersen MA, Hojsted J. Neuropsychological assessment of chronic non-malignant pain patients treated in a multidisciplinary pain centre. Eur J Pain 2005;9:453-62.

Sjögren P, Thomsen AB, Olsen AK. Impaired neuropsychological performance in chronic nonmalignant pain patients receiving longterm oral opioid therapy. J Pain Symptom Manage 2000;19:100-8.

Spielberger CD. Manual for the state-trait anxiety inventory (STAIform Y). Palo Alto, CA: Consulting Psychologists Press; 1983.

Sternberg S. High speed scanning in human memory. Science 1966;153:652-4.

Verster, JC. Measurement of the Effects of Psychoactive Drugs on Driving Ability and Related Psychological Processes. Utrecht, the Netherlands: Thesis, ISBN 9039331324, 2002.

Verster JC, Veldhuijzen DS, Volkerts ER. Residual effects of sleep medication on driving ability. Sleep Med Rev 2004;8:309-25.

Verster JC, Volkerts ER. Antihistamines and driving ability: evidence from on-the-road driving studies during normal traffic. Ann Allergy Asthma Immunol 2004;2:294-304.

Walter H, Vetter SC, Grothe J, Wunderlich AP, Hahn S, Spitzer M. The neural correlates of driving. Neuroreport 2001;12:1763-7.

Ware JE, Snow KK, Kosinski M, Gandek B. SF-36 Health Survey manual and interpretation guide. Boston, MA: The Health Institute, New England Medical Centre; 1993.

Wechsler, D. Manual for the Wechsler Adult Intelligence Scale. New York-III: Psychological Corporation. Dutch translation. Lisse, the Netherlands: Swets \& Zeitlinger B.V., 2000.

Wysenbeek AJ, Klein Z, Nakar S, Mane R. Assessment of cognitive function in elderly patients treated with naproxen. A prospective study. Clin Exp Rheumatol 1988;6:399-400. 